\section{COVID-19: La dificultad de enfrentar a un enemigo cambiante}

\section{COVID-19: The difficulty of facing a changing enemy}

\author{
Aldo Vivar-Mendoza ${ }^{\prime}$
}

Las imágenes del mundo actual parecen salir de una película de ciencia ficción. Las calles vacías, las fronteras cerradas, ninguna circulación por los espacios aéreos o marítimos, salvo los viajes esenciales. La supuesta superioridad tecnológica humana ha sido vapuleada por un simple agente natural y prácticamente ha puesto al mundo en cuarentena, el SARS CoV-2.

El SARS CoV-2, conocido también como coronavirus o por la enfermedad que produce (COVID-19), es un virus de aparición reciente, emparentado con otros miembros notables de la familia Corona, llamada así por las espículas que sobresalen de su cubierta proteica. Son virus que circulan en animales e incidentalmente "saltan" a humanos, en un efecto llamado de "derramamiento". Al momento se conocen siete coronavirus capaces de infectar al ser humano, cuatro de ellos provocan el resfrío común y los últimos tres están ligados a epidemias muy virulentas, el SARS (Severe Acute Respiratory Syndrome), aparecido en 2002 y desaparecido en 2004, el MERS (Middle East Respiratory Syndrome), aparecido en 2014 y aun circulando en camélidos, y, el SARS CoV-2, posiblemente aparecido entre finales de noviembre e inicios de diciembre en un mercado de la comunidad de Wuhan en China, a partir de un salto cualitativo (derramamiento) entre especies animales y humanos, acaso producido por el comercio ilegal de animales, en este caso el pangolín malayo y alguno que otro salto con murciélagos. Es la misma historia vivida con otros virus que lograron el salto de especies, el VIH a partir de monos, el Ébola a partir de murciélagos, el Nipah proveniente de cerdos y el virus de la influenza a partir de las aves. La naturaleza entonces se convierte en un gran laboratorio que alberga mutaciones virales y provee de hospederos potenciales. La expansión de las fronteras urbanas a espacios silvestres expone a los humanos a nuevos agentes infecciosos.

Médico internista. Profesor auxiliar.Universidad Peruana Cayetano Heredia. Hospital Nacional Arzobispo Loayza.
Vivar-Medoza A. COVID-19: La dificultad de enfrentar a un enemigo cambiante. Rev Soc Peru Med Interna. 20 I 9;33(I):7-9.

https://doi.org/10.36393/spmi.v31i2.503

Desde su aparición el SARS CoV-2 se ha diseminado rápidamente por la región sur de China, de allí al resto del país, al resto de Asia y aprovechando de un mundo conectado en cuestión de horas por los viajes internacionales, la epidemia en semanas se transformó en pandemia. Utilizando el hospedero humano y la facilidad del contagio respiratorio, el virus ha atravesado continentes para convertirse en una amenaza a la manera cómo se ha diseñado la vía actual, un comercio y transporte globalizado, grandes ciudades, transporte urbano masivo y un progresivo desmantelamiento del sistema de soporte social a favor de un individualismo a ultranza. De modo invisible pero no menos efectivo, el sistema ha despojado a cierta parte de la humanidad de valores éticos como la solidaridad y la equidad. La llegada de esta epidemia a puesto en cuestionamiento sistemas y valores con unas consecuencias que son imposibles de valorar hasta que no pase el peligro.

La tecnología y la ciencia al día de hoy han logrado descifrar la identidad de este nuevo virus, su modo de transmisión, sus posibles puntos débiles, la patogénesis, el curso clínico, las potenciales armas terapéuticas y prospectos de vacunas, estas últimas dos opciones aun elusivas y pendientes de adecuadas pruebas en campo para mostrar su eficacia, las que si todo sale bien estarían listas recién dentro de un año calendario.

Sin embargo, al margen de todo ello, la principal estrategia descansa en la modificación del comportamiento humano: el distanciamiento social, la adecuada higiene -sobre todo cuando se presenta una infección respiratoria-, el compromiso de las personas para aislarse si tienen síntomas y el sentido de protección mutua entre seres humanos.

Algo que parece tan simple y sin costo se convierte en el reto más difícil. China, acaso aprovechando su estructura política- prácticamente confinó a una comunidad entera Wuhan, con 11 millones de personas-, construyó en menos de dos semanas un hospital ad hoc y puso en cuarentena otras 
ciudades de su vasto territorio. Semanas de intenso trabajo lograron su cometido, desde el primer caso detectado el 31 de diciembre de 2019 las autoridades chinas declararon el 19 de marzo que no habían ocurrido nuevas infecciones. El 20 de enero del 2020 se reportaron los primeros casos fuera de China continental en Japón, Corea del Sur y Tailandia. El 30 de ese mes, ante la magnitud de la epidemia la OMS declara la existencia de una emergencia sanitaria global. Al día siguiente la administración Trump prohíbe el ingreso a territorio estadounidense de extranjeros provenientes de China.

El 11 de febrero la OMS le confiere a la enfermedad su actual nombre, COVID-19 (Coronavirus disease 2019), para entonces China tenía 44653 infectados y 1113 fallecidos, la enfermedad ya se había esparcido a 24 países en diversos continentes.

La migración humana hacía lo suyo. Millones de peregrinos y trabajadores migrantes del mundo islámico atravesaron Irán, dejando una estela de infecciones y muertes, para entonces se convirtió, luego de China, en el segundo país con más infecciones.

El primer caso en América Latina se reportó en Brasil el 26 de febrero, en Perú se hizo lo propio el 6 de marzo. Al momento de iniciar los reportes de infecciones todos los casos de COVID-19 eran importados del nuevo epicentro de la pandemia: Europa, donde dos países han resultado ser los más golpeados, al 30 de marzo ya sobrepasaron a China (81 518 casos) con 101739 casos en Italia y 87956 en España. Sin embargo, el epicentro estaría pronto a cambiar de lugar, los estados Unidos llevan 164253 casos.

El número de casos y el de muertes guarda cierta relación con las características biológicas del virus y la susceptibilidad del hospedero pero al parecer lo más importante es la respuesta sanitaria del país, medida no solo por la fortaleza del sistema de salud, en término de capacidad hospitalaria, recursos humanos o materiales. Al ser el COVID-19 una enfermedad de transmisión respiratoria, sin tratamiento efectivo demostrado y desconociendo la relación entre enfermos y portadores asintomáticos, los pilares del control de la epidemia descansan en la aplicación de estrategias que conducen a detener sus determinantes sociales, el contacto humano, la aglomeración de personas en espacios relativamente estrechos y el desplazamiento de grupos humanos en grandes distancias.

Las respuestas vinieron de la experiencia con la Influenza: cuarentenas, distanciamiento social, higiene. No es fácil detener un país; sin embargo, la experiencia reciente lo ha demostrado, poner primero la salud de las personas sobre el crecimiento económico. La idea es detener la transmisión del virus, matarlo por inanición al no tener a quien infectar y con ello "aplanar la curva" de crecimiento exponencial de una epidemia. Un aumento descontrolado de casos no haría más que colapsar cualquier sistema sanitario sabiendo que el COVID-19 puede terminar en falla respiratoria que requiere el uso de ventilación asistida, los hospitales y sobre todo, las unidades de cuidados intensivos se convierten en los verdaderos cuellos de botella.
El Perú ha respondido temprana y eficazmente en el control de los determinantes sociales de esta epidemia, las medidas de confinamiento y la llamada inmovilidad social, que simplemente es un toque de queda. Sin embargo, a la población le ha costado y le cuesta acatar el orden. Por eso cada semana se ve un endurecimiento progresivo de las normas de confinamiento como en una nueva vuelta de tuerca que ajuste el desorden.

La única gran experiencia previa en epidemias la tienen los peruanos con el cólera, donde el país tuvo el triste privilegio de ser el epicentro de una epidemia que se expandió por toda América Latina, eran otras épocas, casi no había un sistema sanitario formal, la pobreza y la anomia social eran casi hegemónicas, en un medio ambiente insalubre, el vibrión se expandió como pólvora entre agua y alimentos. Sorprendentemente, la letalidad fue baja, de algo sirvió la experiencia de la diarrea infantil que metió en el inconsciente de los médicos peruanos el valor de la rehidratación.

Hoy el COVID-19 encuentra al país en una mejor condición, tanto económica como sanitaria, aunque parece que las medidas sobre los determinantes sociales parecen ser más solidas que las sanitarias; así, en esta epidemia, el conocimiento y la experiencia se construyen día a día. Han ocurrido titubeos casi inaceptables y eso provocó la salida de la ministra de salud. Se tienen hospitales designados para atender los casos de COVID-19 pero hay cierto desorden en los otros establecimientos que ponen en riesgo lo avanzado y sobre todo un riesgo innecesario al personal de salud. Otra historia es el tema de las pruebas diagnósticas que, por su naturaleza, aun son imperfectas y de las que no se conoce bien su precisión, valores predictivos y reproducibilidad. Hay vacíos aun en la vigilancia epidemiológica y se vislumbra cierta confusión acerca de cuál sería el lugar de las potenciales terapias, las que aun no han demostrado eficacia comprobada, pero que algunos promueven con la necesidad de llenar un vacío terapéutico que no es propio del Perú sino del mundo entero.

Ante una epidemia agresiva que se va develando a medida que pasan los días y con el esfuerzo de la comunidad científica global que a diario entrega información, los médicos peruanos, sus instituciones y las organizaciones académicas, tienen un rol trascendental, utilizar la ciencia, en todas sus dimensiones tecnológicas y valores morales, analizar los hechos concretos en su contexto, sin juicios de valor, sin intereses personales o grupales con el objetivo de tomar las mejores decisiones con los recursos disponibles. Combatir una epidemia es como pelear una guerra, hay armas y soldados, generales y servicios de inteligencia, las discrepancias y la discusión son permitidas, que se entienda que no son fisuras ni traiciones sino la voluntad de encontrar la mejor estrategia. La inteligencia es nuestra mejor arma, la firmeza una vez tomadas las decisiones nuestro norte. En estas situaciones, las experiencias ajenas que se publican a diario son valiosísimas pues funcionan como lecciones aprendidas, pero es bueno recordar que no deben ser copiadas literalmente pues no existen dos sociedades y 
sistemas políticos iguales. La evidencia científica debe ser evaluada desde diversos puntos de vista hasta encontrar el modelo apropiado a nosotros, de no ser así corremos el riesgo de que las normas decretadas sean un espejo deforme de nuestra realidad y peor aun que la realidad la termine sobrepasando haciéndola obsoleta e ineficaz en solo unos días.

El retiro de grupos humanos de ciertos espacios ha permitido observar la armonía, superioridad e inmutabilidad de las leyes de la naturaleza, de un ecosistema que se sana y renueva, es hora de demostrar que estamos a su altura.

\section{REFERENCIAS BIBLIOGÁFICAS}

La literatura sobre COVID-19 es copiosa y de acceso libre. E autor ha revisado los sitios web de The Lancet, New England Journal of Medicine, JAMA, Annals of Internal Medicine, National Institutes of Health, Centers for Disease Control, World Health Organization, Ministerio de Salud del Perú, así como múltiples portales web de los principales diarios del Perú y el mundo.

Lima, 30 de marzo del 2020 